\title{
THE ACHIEVEMENT OF HIGH SCHOOL AND FRESHMAN COLLEGE STUDENTS IN CHEMISTRY.
}

Bx S. R. Powers, Director of tije Training School.

University of Arkansas.

During May, 1920, two chemistry tests, described below were given in 20 high schools located in the central and north-central states. The enrollment in the high school classes taking the test varied from 5 to 171 . The tests were also given to two groups of Freshmen enrolled in the chemistry classes in a large mid-western university. 'These students were at the poin' of finishing the Freshman work in university chemistry. One of the Freshman groups consisted of 168 engineering students, 151 of whom had taken one year of high school chemistry before entering the university. The second Freshman group consisted of 57 students, none of whom had taken any chemistry in high school.

This preliminary report is limited to results obtained from four large schools and from the two groups of University Freshmen, or in all six groups of students. Each of these groups, except the university Freshmen who had not taken high school chemistry, took both of the tests. This group of the university Freshmen took only the part of the test described below as Test I. The four high schools were located in four different states. The designation of these groups used in this report together with the number of students in each group is:

$\begin{array}{cc}\text { School } & \text { Cases } \\ \text { A } & 46 \\ \text { B } & 81 \\ \text { C } & 121 \\ \text { D } & 171 \\ \text { U } & 168 \\ \text { Ux } & 57\end{array}$

The group designated $\mathrm{U}$ represents those university Freshmen, who had taken chemistry in high school, and the group Ux represents those Freshmen who had not taken chemistry in high school. Each of the university groups was tested just before the end of one year's work in college chemistry.

The tests were circulated from the University of Minnesota. They were designated as Test I and Test II. It was intended that each test be of such length that it would require one class period for students to finish. The time element was not considered in scoring and it was intended that students should not feel unduly rushed while taking the test. The examiner hoped that the student would feel when he handed in his paper that he had 
answered as much of the test as he was able to answer. The results of the testing show that most of the students taking the test were allowed ample time.

As respects the material constituting them, the two tests differed from each other quite distinctly. Test I called for ability to perform more or less mechanical operations and involved the use of formulas and equations. Test II tested the student's range of informational facts, which he had been taught in the chemistry course.

Test I was divided into eight groups of items. It seems inadvisable to reproduce the complete tests here. The nature of the test will be clear, however, from the following, which are the instructions as given for each group of items, together with one item for illustration. The number of items in each group is also indicated.

\section{Test I.}

I. Write the names of the following compounds:

1. $\mathrm{Hg} \mathrm{O}$ (Ten formulas constitute Group I)

II. Write the formula for the following substances:

1. Calcium oxide. (The names of ten substances constitute Group II)

III. The valence of the following elements and radicals are as indicated. Write the formula for the oxide, bromide, sulfate, and phosphate of each metal.

$\mathrm{Mg}^{+}+{ }_{\mathrm{S}} \mathrm{O}^{--}$(The valenee of five positive and four negative radieals are indicated and space is left for the student to write 20 formulas.)

IV. Arrange the following elements in order of tho activity series (displacement series). (The names of 10 electropositive elements are given and blanks left in which the students are to arrange them in order.)

V. Place a letter C before each substance listed here if it is a compound, a letter $E$ if it is an element, and a letter $M$ if it is a mixture.

1. - Cane sugar. (The names of 20 substances eonstitute the group.)

VI. Fill in the right hand side and balance each of the following equations:

$\mathrm{Zn}+\mathrm{H}_{2} \mathrm{SO}_{4} \rightarrow$ (Ten equations constitate the group.)

VII. Write the equation for each of the following chemical changes:

1. The preparation of oxygen from potassium ehlorate. (Ten chemical changes are named and space left for the equation for each.)

VIII. Write one equation to illustrate each of the following types of reactions:

1. Simple addition. (Illustrations are asked for five types of reactions.)

The nature of Test II is made clear by the statement of the instructions to the students together with the illustrations. The instructions are: "This is a test of range of information about chemistry. In each of the following statements you have five ehoices for the last word. Only one of them will make the 
sentence correct. In each sentence draw a line under the one of these words which makes the truest sentence. Notice the sample sentences:

Water is a compound of hydrogen and zinc nitrogen oxygen helium chlorine.

The word oxygen is underlined because it makes the truest sentence. Complete as many of the sentences as you can."

1. The oxygen of commerce is made chiefly from water potassiumchlorate barium peroxide liquid air sodium peroxide. (One hundred such incomplete sentences constitute Test II.)

The tests were scored by recording the number of times each item in each test was answered correctly. A detailed report, showing the score on each of the 195 items included in the two tests, would occupy more space than the conditions under which this preliminary report is published could justify. This summary report gives only averages and medians.

In Table I is shown the percent of perfect scores made by each school on each of the eight groups of items of Test I. For example the 80 at the head of the first column means that 80 percent of the answers made to the ten items in group I of Test I by the students in school A, were correct.

TABLE I.

Cases: $\quad$ A-46; B-81; C-110; D-165; Total H. S. -402

\begin{tabular}{|c|c|c|c|c|c|c|c|c|c|}
\hline Part & $\begin{array}{c}1 \\
80.0\end{array}$ & $\begin{array}{c}2 \\
49.1\end{array}$ & $\begin{array}{c}3 \\
86.4\end{array}$ & $\begin{array}{c}4 \\
41.0\end{array}$ & $\begin{array}{c}5 \\
64.3\end{array}$ & $\begin{array}{c}6 \\
48.2\end{array}$ & $\begin{array}{c}7 \\
31.0\end{array}$ & $\begin{array}{c}8 \\
45.6\end{array}$ & $\begin{array}{c}\mathrm{Av} . \\
55.8\end{array}$ \\
\hline & & 40 & 81.1 & 53.3 & 54.0 & 44 & & 45.4 & \\
\hline & & 56 & 88 & & 68 & & & 53.6 & \\
\hline & 56 & 31. & & 28 & & & & & \\
\hline & & & & & & & 29 & 50 & \\
\hline & 86 & 67 & 95 & 3 & 82.5 & 60.1 & 44.8 & 70.8 & \\
\hline & 80.7 & $\tilde{5} 1$. & 95.8 & 54.8 & 78.6 & 52.6 & 33.6 & 65.2 & \\
\hline
\end{tabular}

The highest score of the high schools was made on the items in Group III which calls for ability to write formulas from given radicals and their valences. The next highest score was made on Group I which called for ability to write the names of compounds from given formulas. The third highest seore was made on Group V which called for ability to classify elements, mixtures and compounds. On only these three groups of items was the percent of correctness higher than 50. The lowest score was made on the items grouped under VII. These items called for ability to write equations from the name or description of given chemical changes.

The differences between the highest and lowest high school scores on Test I, between the scores of the two university classes 
and between the highest high school score and each of the university classes is important for purposes of comparison. These are shown in Table II.

Table II.

\begin{tabular}{|c|c|c|c|c|c|c|c|c|c|}
\hline \multirow{5}{*}{$\begin{array}{l}\text { Difference between } \\
\text { lowest and } \\
\text { highest } H . S \text {. } \\
\text { highest H.S.\& U. } \\
\text { Highest H. S. \& Ux. } \\
\text { U and Ux. }\end{array}$} & & \\
\hline & & & & & & & & & \\
\hline & 23.3 & 24.2 & 29.8 & 25.8 & 14.6 & 20.6 & & & \\
\hline & & & 6.8 & $18.4^{*}$ & & 11.9 & 13.8 & 17.2 & \\
\hline & $\because \because$ & $4.8^{*}$ & 7.5 & 1.5 & 10.0 & 4.4 & 2.6 & 11.6 & \\
\hline $\mathrm{U}$ and Ux. & & $\begin{array}{l}15.9 \\
\text { est. }\end{array}$ & 0.7 & $19.9 \dagger$ & 3.9 & 7.5 & 11.2 & 5.6 & \\
\hline
\end{tabular}
items the range between the highest and the lowest high school scores is much greater than the range between the highest high school and either of the university scores. On six of the eight groups of items the university students who had had high school chemistry did considerably better than those who had not had high school chemistry. We do not have in this any basis for definite conclusions, but if ability to answer the items given in Test $I$ is any index of general ability in chemistry, we may well question whether the criticisms of high school chemistry teaching made by university chemistry teachers has any scientific foundation. When we recognize further that those students who finish the Freshman year in a university represent a much more highly selected group as regards ability to do school work than those students enrolled in our high school classes and when we consider that the equipment furnished by the university is usually superior to that of the high schools and thirdly, that the university students are actually required to devote more hours per week to chemistry than high school students devote, it would seem that, given these just named conditions equal, measured in terms of Test I, the product from our high school classes in chemistry is not materially different from the product from our university Freshman classes.

Table-III is inserted to show the average scores made by boys and girls on each of the eight groups of items in Test I.

Only in school D were the girls able to excel the boys and here only in two groups of items. It may occasion some surprise to see that in these more or less mechanical operations the boys should so consistently excel the girls.

Test II requires a somewhat different ability than that required for Test I. This test is supposed to measure the student's range of information about chemistry; it is presumed to give a relative measure of the number of facts about chemistry which 
the student has learned. Students deficient in the ability required for this test have probably profited but little from their instruction. It is hardly conceivable that they could succeed in any test if they were lacking in information.

\begin{tabular}{|c|c|c|c|c|c|}
\hline \multicolumn{6}{|c|}{ TABLe III. } \\
\hline Schools & Cases & I & II & III & IV \\
\hline A. & b. ${ }_{21}$ & $\begin{array}{l}\text { b. } \\
84.8\end{array}$ & b. $\stackrel{\mathrm{g}}{58}$ & b. $\stackrel{\text { g. }}{8{ }^{2}}$ & b. $\quad$ g. \\
\hline$B$. & $53 \quad 28$ & 77.964 .6 & $44.0 \quad 34.3$ & 82.080 .5 & 59.041 .8 \\
\hline & $65 \quad 55$ & 76.072 .5 & 63.955 .7 & 83.590 .0 & \\
\hline D. & 6590 & 61.155 .5 & 29.232 .5 & 62.059 .0 & 31.228. \\
\hline Av. & $204 \quad 198$ & $\underset{V}{73.6} 64.1$ & ${ }_{\text {VI }}^{44.139 .8}$ & $\begin{array}{l}64.567 .0 \\
\text { VII }\end{array}$ & $\begin{array}{c}46.032 . \\
\text { V III }\end{array}$ \\
\hline A. & & $\begin{array}{l}\text { b. } \\
72.5 \text { g. }\end{array}$ & $\begin{array}{l}\text { b. } \\
56.6 \\
42.8\end{array}$ & $\begin{array}{l}\text { b. } \\
43.8 \\
20.4\end{array}$ & $\begin{array}{l}\text { b. } \\
55.6 \\
36 .\end{array}$ \\
\hline B. & & $72.5 \quad 60.5$ & 49.033 .8 & 311314.6 & 54.026 \\
\hline C. & & $70.5 \quad 67.0$ & $\begin{array}{lll}46.3 & 43.8\end{array}$ & $30.9 \quad 28.9$ & 56.851 \\
\hline D. & & $65.5 \quad 61.5$ & 30.725 .0 & $17.0 \quad 15.2$ & 51.247. \\
\hline Av & & 69.062 .5 & 43.136 .2 & $27.9 \quad 19.6$ & $54.4 \quad 44$ \\
\hline
\end{tabular}

The median scores made by each of the schools and by the boys and girls in each school together with the number of students taking Test II are shown in Table IV.

\begin{tabular}{lcrrrrr} 
Schools & \multicolumn{7}{c}{ Table IV. } \\
& $\begin{array}{c}\text { Group } \\
\text { Med. }\end{array}$ & Cases & $\begin{array}{c}\text { Girls } \\
\text { Med. }\end{array}$ & Cases & Boys & Cases \\
A. & 47.3 & 38 & 42.0 & 19 & 56.0 & 19 \\
B. & 41.2 & 80 & 39.0 & 30 & 44.0 & 50 \\
C. & 38.0 & 108 & 38.0 & 52 & 37.0 & 56 \\
D. & 38.9 & 171 & 37.5 & 92 & 39.5 & 62 \\
Av. & 39.1 & & 38.2 & & 41.5 & \\
U. & 56.5 & 168 & & & &
\end{tabular}

Only the group of university students who had taken high school chemistry took Test II.

In Test II as in Test I the difference between the median scores made by the university and high school students was not grcat. The range between the highest and lowest median scores made by the high schools is just equal to the range between the highest high school median score and the median score of the university students. It is noteworthy that in Test II as in Test I the boys scored uniformly higher. In school $\mathrm{C}$, the single exception, the median of the girls is one point higher than the median of the boys.

The relation between the ages of the students and their test scores is interesting and probably significant. Table $\mathrm{V}$ shows this relation. Only data from schools $\mathrm{B}, \mathrm{C}$ and $\mathrm{D}$ are used in this table. Notice that the younger students uniformly make the highest scores. The 20 year old group consisting of but 16 students constitutes the sole exception. These students scored higher than the 18 and 19 year olds but lower than all others. 
The facts shown here are, however, as one would expect them to be. It takes an intelligent youngster to make enrollment in the chemistry class, a junior or senior subject, by age 15 . With the degree of intelligence that could win this rapid promotion the youngest students should make the highest scores when given any sort of objective tests. The age scores in Table V are averages.

Taula V.

Av. 15yr.Cases 16yr.Cases 17yr.Cases 18yr. Cases 19yr.Cases 20yr.Cases

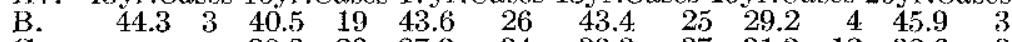
$\begin{array}{llllllllllll}\text { C. } & & 39.9 & 20 & 37.3 & 34 & 33.3 & 37 & 31.3 & 12 & 32.6 & 3\end{array}$

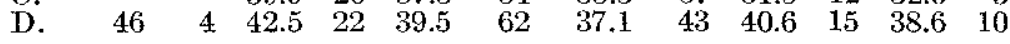
$\begin{array}{lllllllllllll}\text { Av. } \quad & 45.2 & \overline{7} & 41.0 & \overline{61} & 39.8 & \overline{122} & 37.2 & \overline{105} & 35.5 & \overline{31} & 38.8 & \overline{16}\end{array}$

It is a significant fact to chemistry teachers that the order of difficulty of the various items of the test in different schools is nearly the same. Those items found to be most difficult by one school were generally found to be most difficult by all schools. This fact is strikingly illustrated by arranging the scores, which were made on the various items of the test in rank order, and determining the correlation between the numbers expressing this rank order in different schools. In Test $I$ the items of each division of the test were rank-ordered according to the score on each item and the correlation between the numbers expressing the rank order determined for three schools. These values are shown in Table VI. It was impossible to give a rank order for the items in division III and IV.

Correlation between

$\begin{array}{lclllll}\text { schools } & \text { I } & \text { II } & \text { V } & \text { VI } & \text { VIr } & \text { VIII } \\ \text { A and B } & .77 & .88 & .79 & .94 & .77 & .98 \\ \text { B and D } & .84 & .92 & .50 & .94 & .72 & .90 \\ A \text { and D } & .80 & .88 & .57 & .86 & .74 & .60\end{array}$
TABLE VI.

The order of difficulty for the items in divisions I, II, VI and VII which call only for knowledge of formulas and equations is more nearly the same in the different schools than for the items in division $\mathrm{V}$ which calls for ability to classify elements, mixtures and compounds. The factors under number VIII are not significant for the reason that there are only five items in this division.

The relation between the order of difficulty for the items in Test II was determined in the same way. The scores made on each of the 100 items of the test in each of the four schools were put in rank order. The numbers expressing this rank order in the different schools were then correlated. The values obtained 
are shown in Table VII. The formula used for calculating these correlations and also those in Table VI is: $r=-\frac{6 \mathrm{sum} \mathrm{d}^{2} \text {, }}{\mathrm{N}\left(\mathrm{N}^{2}-1\right)}$ $r$ is the correlation factor, $n$ is the number of cases and $d$ is the difference between numbers expressing the rank order.

Correlation between TABLE VII.

$\begin{array}{ll}\mathrm{A} \text { and } \mathrm{B} & \mathrm{r} \\ \mathrm{B} \text { and } \mathrm{C} & .47 \\ \mathrm{~B} \text { and } \mathrm{D} & .50 \\ \mathrm{C} \text { and } \mathrm{D} & .55 \\ & .54\end{array}$

The following illustrations will make clear the significance of the factors in Table VII. In determining these values it was necessary to determine by subtraction the difference between the numbers used to express the rank orders of difficulty of a given item in the two schools between which the correlation was determined. For example, if one item in the test was found easiest in one school that item would be given rank one in that school. If it was found most difficult in another school it would in this school be given rank 100 (100 items constitute the test). The difference between the numbers expressing the rank in the two schools would be 99 . If the order of difficulty for a given item is the same in two schools the difference between the numbers expressing the rank would be zero. In determining the correlation between schools $\mathrm{A}$ and $\mathrm{B}$, the case in which the correlation factor is lowest, it was found that 31 of the differences between the numbers expressing the rank orders were less than $10 ; 51$ differences were less than 20 , and only 13 were greater than 50 . In determining the correlation between $\mathrm{B}$ and $\mathrm{D}$, in which the factor was found to be greatest, 34 of the differences between the numbers expressing the rank orders were less than $10 ; 62$ were less than 20 and but 5 were greater than 50 . It would seem, therefore, that those points of information which are emphasized in one of these schools are also emphasized in the other schools. Certainly the agreement between these schools as regards course content is surprisingly high.

This paper is presented for the purpose of giving results of the test. However, it is difficult to refrain from adding comment. There is occasion for surprise that students do so poorly on certain parts of the test and so well on other parts. Test I shows that only 76 percent of the students in these four high schools knew that air was a mixture. Only 53 percent knew that coal gas was a mixture. Only 12 percent of these students were able 
to eomplete our pet equation for the preparation of sulfur dioxide from copper and sulfuric acid. Only 5.3 percent were able to write the equation to represent the laboratory preparation of ammonia, using ammonium chloride. The students found it very easy to recognize or to write the formula of the common laboratory reagents but found difficulty with any that were unusual. The part of Test I that occasioned greatest difficulty was that of writing the equation for a chemical change when there is given the name or description of the change (Group VII). The difficulty experienced by both the high school and university groups with the items in Group VII would seem to indicate either that teachers are not trying to develop this ability or that the realization of this ability lies beyond the capacity of high school students.

Test II is of sufficient importance to merit a detailed report on each of the 100 items in the test. However, it seems advisable to withhold such a report until the test has been revised. This report will mention only particular items. The point in this test that was most generally known was that water may be separated into hydrogen and oxygen by electrolysis. Ninety percent of all the students in the four schools answered this point correctly. The question of whether or not air is a mixture is next in order of difficulty. Eighty-four and one-half percent of the students answered this correctly. The third point in order of difficulty required the student to say what part of a liter 200 cubic centimeters is. Eighty-four percent answered this correctly. One can scarcely understand how 16 percent of the students enrolled in four of the best high schools in the United States could fail when asked to answer these second and third points and that 10 percent should miss the first one.

The point of greatest difficulty required that the students tell whether gas mantles were made from asbestos, thorium oxide, magnesium oxide, thermit or styptic cotton. Only 6.7 percent of all the students answered this point correctly. A surprisingly large number answered styptic cotton. Next to the most difficult was the fact that wool contains sulfur in chemical composition while silk does not. Eight and six-tenths percent of the students were familiar with this fact. Whether or not palmatin is contained in butter, soap, petroleum, coal tar or slag, with eleven percent of correct answers, was next in order. The average of the median percent scores on Test II in the four schools is 39.1 . 
The teachers who gave the tests were asked to rate their students on three items, namely, scholarship, industry and intelligence. Scholarship was defined in terms of achievement. Teachers were asked to rate those students who had actually learned the most about chemistry as highest in scholarship. They were asked to rate the most industrious students, that is, those who tried hardest, as highest in industry, and to rate the most intelligent, that is, those who learn with least effort, as highest in intelligence. The ratings on each quality were made in terms of $\mathrm{A}, \mathrm{B}, \mathrm{C}, \mathrm{D}$, and $\mathrm{E}$. The teachers were guided in making their ratings by the following instructions:

Scholarship: In rating a pupil in scholarship, think about how well he does in his school studies. If he is average, mark him C. If he is as good as the best 5 percent of children you have known in the public school, marks him A. If he is better than the poorest 75 percent of the public school children you know, but not so good as the best 5 per cent, mark him B. If he is poorer than the best 75 per cent you have known, i. e., poorer than the middle 50 percent, but not so poor as the poorest 5 percent, mark him D. If he is as poor as the poorest 5 percent of children in the public schools, mark him E. Proceed similarly with every other child on the list. 1

No ratings were made by sehool $A$. Those from schools $B$ and $\mathrm{C}$ were incomplete, only about half the students of each school were rated. Only from school $D$ was a rating furnished for each student taking the test. In tables VIII and IX are given the median or average ${ }^{2}$ test scores and the range of scores falling within the middle 50 percent of the scores made by the students coming under each scholarship rating. In other words, 25 percent of the students falling under each scholarship rating made poorer and 25 percent made better than the lowest and the highest score given in the tables under range. Table VIII shows the results from Test I and Table IX shows the results from Test II. The total score for Test I was gotten by adding the scores made on each of the eight groups of items which constitute the test. The possible total score is 95 . The scores on Test II were gotten by adding the total number of correct answers which the student made on the test. The total possible score is 100 . Table $\mathrm{X}$ is arranged in the same manner as Tables VIII and IX. It differs in that the scores in this table were obtained by adding the scores made on Test I and Test II.

! These instructions were taken from a form used by the Virginia Survey Commission.

2 Averages were computed when the number of cases was small. 
Table VIII.

Test I seores

\begin{tabular}{|c|c|c|c|c|c|c|}
\hline Tracher: & ratings & A & st & & B & \\
\hline Sehools & Cases & Med & Range? & Cases & Med & Range \\
\hline $\mathrm{B}$ & 5 & 76.4 & $74-80$ & 12 & 58.0 & $51-67$ \\
\hline $\mathrm{C}$ & 4 & 63.0 & & 7 & 56.8 & $58-62$ \\
\hline $\mathrm{D}$ & 30 & 47.0 & $40-55$ & 34 & 41.4 & $36-45$ \\
\hline Teachers & ratings & $\mathrm{C}$ & & & $\mathrm{D}$ & $\mathrm{E}$ \\
\hline Schools & Canses & Med & Range & Cases & Med & Range Casse \\
\hline B & 26 & 47.5 & $35-54$ & 3 & 42.0 & 0 \\
\hline $\mathrm{C}$ & 16 & 53.6 & $48-63$ & 24 & 50.5 & $40-57$ \\
\hline D & 69 & 37.2 & $33-41$ & 26 & 32.3 & $29-39$ \\
\hline & & & $\begin{array}{l}\text { Table } \\
\text { Test II }\end{array}$ & x. & & \\
\hline Teachers & ratings & A & & & B & \\
\hline Sehools & Cases & Med & Range & Cases & Med & Range \\
\hline $\mathrm{B}$ & 5 & 53.4 & $\ldots \ldots \ldots$ & 9 & 43.1 & $36-47$ \\
\hline$\stackrel{\mathrm{C}}{\mathrm{D}}$ & $\begin{array}{r}3 \\
29\end{array}$ & $\begin{array}{l}46.6 \\
60.5\end{array}$ & $52-68$ & $\begin{array}{c}6 \\
33\end{array}$ & $\begin{array}{l}41.0 \\
49.6\end{array}$ & $36-57$ \\
\hline 'Teachers & ratings & $\mathrm{C}$ & & & $\mathrm{D}$ & $\mathrm{E}$ \\
\hline Schools & Cases & Med & Range & Cases & Med & Range Cases \\
\hline $\mathrm{C}$ & $\begin{array}{l}22 \\
14\end{array}$ & $\begin{array}{l}39.5 \\
34.6\end{array}$ & $\begin{array}{l}35-43 \\
31-42\end{array}$ & 24 & 32.5 & $29-38$ \\
\hline D & 73 & 39.4 & $30-46$ & 26 & 29.5 & $25-43$ \\
\hline & & & TABLE & & & \\
\hline & & Test & td II seo & combir & ed. & \\
\hline Teachers & ratings & A & & & B & \\
\hline Schools & Cases & Med & Range & Cases & Med & Range \\
\hline $\mathrm{B}$ & 5 & 129.8 & & 9 & 102.6 & $95-109$ \\
\hline $\mathrm{C}$ & 3 & 108.0 & $93-116$ & 7 & 95.5 & $80-97$ \\
\hline Teachers & $\begin{array}{c}29 \\
\text { ratings }\end{array}$ & $\begin{array}{c}106.0 \\
\mathrm{C}\end{array}$ & & 33 & $\begin{array}{l}89.2 \\
\mathrm{D}\end{array}$ & $\mathrm{E}$ \\
\hline Schools & Cases & Med & Range & Cases & Med & Range Cases \\
\hline$\stackrel{\mathrm{B}}{\mathrm{C}}$ & $\begin{array}{l}23 \\
14\end{array}$ & $\begin{array}{l}84.0 \\
88.8\end{array}$ & $\begin{array}{l}77-97 \\
69-105\end{array}$ & $\begin{array}{r}1 \\
24\end{array}$ & 275 & $\begin{array}{l}0 \\
1\end{array}$ \\
\hline $\mathrm{D}$ & 70 & $\begin{array}{l}70.0 \\
73.8\end{array}$ & $66-84$ & 26 & 63.0 & $60-77$ \\
\hline
\end{tabular}

The ratings from school $\mathrm{D}$ are most significant for the reason that the instructors here gave a scholarship rating for each student taking the test. The results from this school are illustrative and probably typical of what would be found in other schools. The amount of overlapping of the scores made on Test I by the students in the various scholarship groups of School D is clearly shown by Figure I. Figure II shows the same thing for Test II and Figure III represents the overlapping of the scholarship groups when the scores made on Test I and Test II are combined. A line representing the range of scores made on Test II by the university group is added to Figure II for comparison. The length of the lines represents the complete range between the highest and lowest score in each scholarship group. The heaviest cross bar on the line represents the position of the ${ }^{3}$ Range as used in this table means range of the middle 50 por cont of the scores made
by the students taking the tcsts. 
median score for the group. The distance between the two lighter cross bars on the line represents the range between the scores made by the students who make up the middle 50 percent of the group.

\section{FIGURE I.}

Range of scores, range of middle 50 per cent and the median score of students falling in each teacher's rating group. School D, Test I.

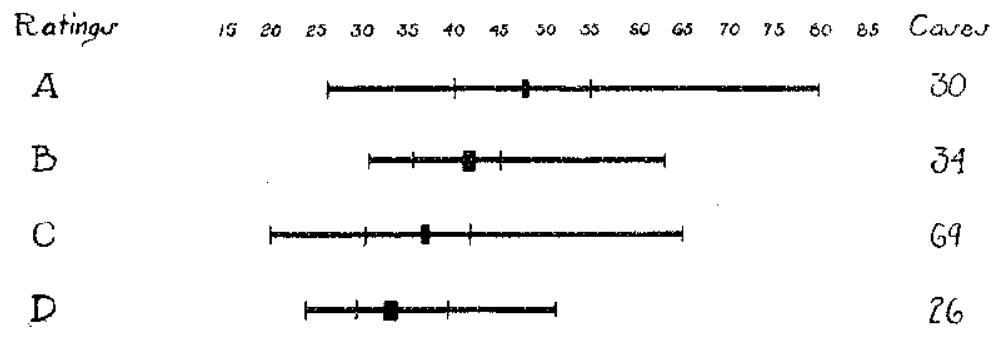

Figure II.

Range of scores, range of middle 50 per cent and the median score of students falling in each teacher's rating group, School D, and the range of seore, range of middle 50 per cent and the median score of the University freshmen, Test II.

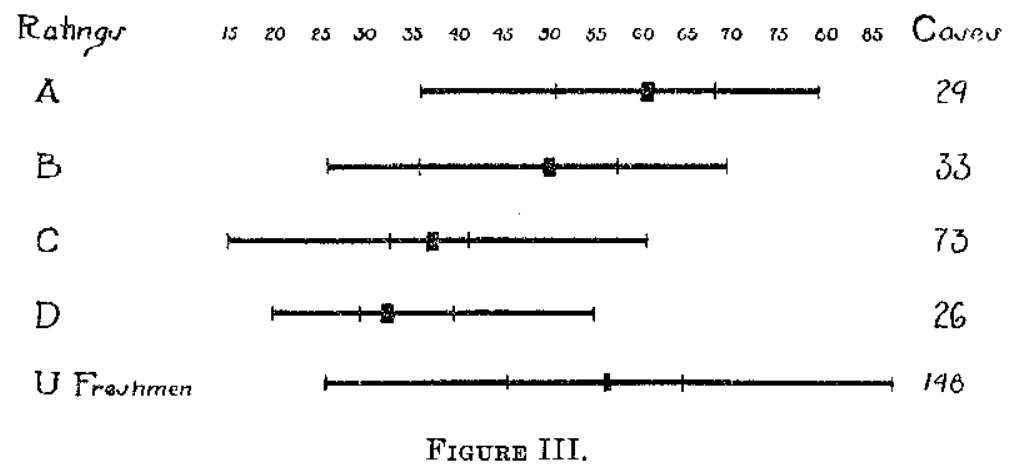

Range of scores, range of middle 50 per cent and the median score of students falling in each teacher's rating group, School D, Tests I and II combined.

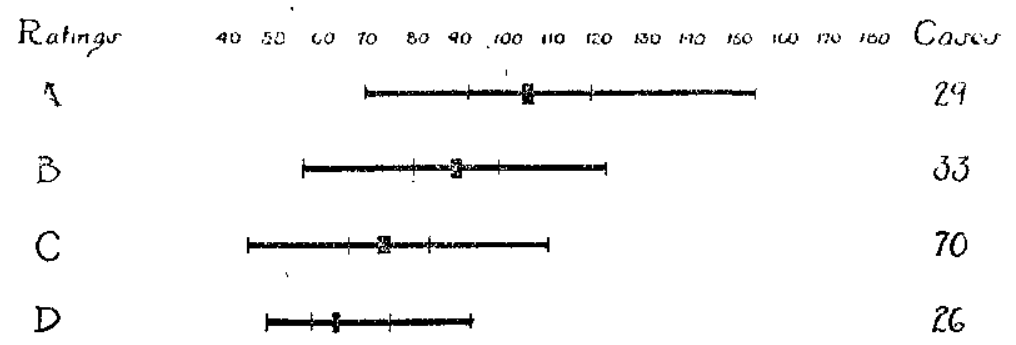


The position of the median score for each group shows a general agreement between test scores and teachers' ratings for scholarship. The overlapping of the scores of the various scholarship groups may be due to many causes. In the first place, it is not assumed that the tests measure all those qualities which should be considered in making marks. It is conceivable that students who usually do well might do poorly on a single test. Adding the scores of the two tests should give a more accurate measure of the ability of individual students. The agreement between test scores and teachers' rating must be far from exact for the inaccuracies of teachers' estimates are well known. It seems quite likely, however, that these tests give a more accurate measure of the ability of individual students than any other single thing that could be used.

The results from our first experience with measuring the product from instruction in chemistry are most gratifying. On the basis of these results the tests are now being revised. The revised tests will be circulated near the close of the school year (1920-21) in what is hoped will be a final form.

The author of this study is very grateful, indeed, to those chemistry teachers who cooperated so generously by giving these tests and scoring the results. He sincerely hopes that when the revised tests are circulated the teachers will again lend their cooperation and thus make possible the formulation of a useful scale for measuring the results which accrue from giving instruction in chemistry to high school students.

\section{AN ELEMENTARY DIFFRACTION METHOD FOR MEASURE- MENT OF WAVE LENGTH}

By J. K. RoBertson, Queens University, Kingston, Canada

When plane waves of monochromatic light fall on a small circular aperture and the emergent light is observed in an eyepiece placed at any position along a normal to the plane of the aperture, the diffraction pattern in general consists of alternately bright and dark circular rings with a bright or dark centre. If the eye-piece be moved from a considerable distance towards the aperture, it passes through fairly well-defined positions in which the central portion of the diffraction pattern is of maximum or of minimum intensity. Successive positions are somewhat as indicated in Fig. 1. 